\title{
The Neonatal Microbiome and Its Partial Role in Mediating the Association between Birth by Cesarean Section and Adverse Pediatric Outcomes
}

\author{
Diana Montoya-Williams ${ }^{a}$ Dominick J. Lemas ${ }^{b}$ Lisa Spiryda ${ }^{c}$ Keval Patel $^{b}$

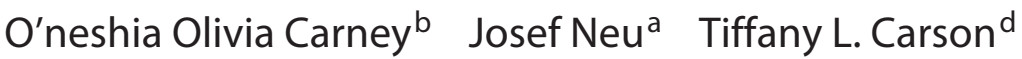 \\ a Division of Neonatology, Department of Pediatrics, University of Florida, Gainesville, FL, USA; \\ ${ }^{b}$ Department of Health Outcomes and Biomedical Informatics, University of Florida, Gainesville, FL, USA; \\ 'Department of Obstetrics and Gynecology, University of Florida, Gainesville, FL, USA; ${ }^{\mathrm{d}}$ Division of Preventive \\ Medicine, Department of Medicine, University of Alabama at Birmingham, Birmingham, AL, USA
}

\section{Keywords}

Dysbiosis · Lactobacillus · Bifidobacterium .

Mode of delivery $\cdot$ Child health

\begin{abstract}
Background: Cesarean sections (CS) are among the most commonly performed surgical procedures in the world. Epidemiologic data has associated delivery by CS with an increased risk of certain adverse health outcomes in children, such as asthma and obesity. Objective: To explore what is known about the effect of mode of delivery on the development of the infant microbiome and discuss the potentially mediating role of CS-related microbial dysbiosis in the development of adverse pediatric health outcomes. Recommendations for future inquiry are also provided. Methods: This study provides a narrative overview of the literature synthesizing the findings of literature retrieved from searches of PubMed and other computerized databases and authoritative texts. Results: Emerging evidence suggests that mode of delivery is involved in the development of the neonatal microbiome and may partially explain pediatric health out-
\end{abstract}

\section{KARGER}

(c) 2018 S. Karger AG, Basel

E-Mail karger@karger.com

www.karger.com/neo comes associated with birth by CS. Specifically, the gut microbiome of vaginally delivered infants more closely resembles their mothers' vaginal microbiome and thus more commonly consists of potentially beneficial microbiota such as Lactobacillus, Bifidobacterium, and Bacteroides. Conversely, the microbiome of infants born via CS shows an increased prevalence of either skin flora or potentially pathogenic microbial communities such as Klebsiella, Enterococcus, and Clostridium. Conclusions: Mode of delivery plays an important role in the development of the postnatal microbiome but likely tells only part of the story. More comprehensive investigations into all the pre- and perinatal factors that have the potential to contribute to the neonatal microbiome are warranted.

(c) 2018 S. Karger AG, Basel

\section{Introduction}

Postnatal microbial colonization of the human gastrointestinal track plays a critical role in health and disease [1]. Recently, the concept that infants are born sterile has
Dominick J. Lemas, $\mathrm{PhD}$

Department of Health Outcomes and Biomedical Informatics, University of Florida 2004 Mowry Road

Gainesville, FL 32610 (USA)

E-Mail djlemas@ufl.edu 
been called into question by studies demonstrating a diverse microbial community in amniotic fluid, placental samples, and meconium $[2,3]$. Accumulating data has shown that cesarean section (CS) alters the infant microbiome $[4,5]$, with the subsequent microbial dysbiosis being implicated in an increased risk of adverse outcomes such as asthma, obesity, diabetes, and allergies [6-8]. Given that CS is one of the most common surgical procedures performed today, with CS rates in developed countries far exceeding the recommended rates [9], the mechanisms potentially linking CS to deleterious health outcomes are particularly important to understand.

One mechanism believed to link CS and later disease is the hygiene hypothesis and the differential exposure to maternal microbiota experienced by infants born via CS versus vaginal delivery $[8,10]$. Due to the potential for CS to modify the development of the infant microbiome and potentially affect long-term health outcomes, this review explores: (1) the impact of CS birth on the development of the infant microbiome and (2) known associations between the perinatal microbiome and subsequent health outcomes in children born via CS. It ends with a brieflook at other maternal factors which merit investigation due to their potential to mediate or even mitigate the effect of mode of delivery on the development of the neonatal and pediatric microbiome.

\section{Methods}

Initial searches were conducted in PubMed with the assistance of a reference librarian. We searched PubMed for MeSH headings and keywords to identify publications for inclusion. The only limits applied were date (original reports published from 2010 to 2015; review papers published from 2013 to 2015) and language (available in English). Separate searches were performed for each of the topics covered in this review. Combinations of search terms for each topic and the number of papers yielded are displayed in online supplementary Appendix 1 (for all online suppl. material, see www.karger.com/doi/10.1159/000487102).

For each individual search, all results were combined into a reference database. Then, duplicates were deleted. For the first elimination step, studies that were clearly not relevant based on the title were removed. Next, the remaining abstracts were reviewed and those not relevant to the topic were removed. For all remaining papers, the full text of the paper was read to determine whether relevant information was included. After reviewing the full text of eligible papers, additional targeted searches were conducted to retrieve seminal papers that may have fallen outside of the prespecified data range or to further search for references to answer questions in more detail than possible with the first round of limited searches.

The following discussion will be organized into 3 main sections. First, associations between mode of delivery and microbial colonization patterns will be explored. Second, we will describe the pediatric outcomes that have been epidemiologically linked to birth by CS and CS-associated microbial communities. Finally, we will end with a short overview of other factors such as stress, diet, breastfeeding and maternal antibiotics that are also believed to be influential in the development of the neonatal microbiome. Recommendations for future research are provided based on the potential for these factors to mediate or even mitigate the effect of mode of delivery on the development of the neonatal and pediatric microbiome.

\section{Associations between Mode of Delivery and Microbial}

\section{Colonization}

Until recently, the fetal gastrointestinal tract was believed to be sterile, destined to become colonized at birth through contact with the microbial community of the vaginal canal $[11,12]$. This "sterile womb" hypothesis emerged from studies using traditional culture-based techniques that reported finding no bacteria in amniotic fluid or meconium samples from infants born after healthy pregnancies [13]. Under this paradigm, it was presumed that infants delivered by CS were devoid of early colonization and began with a "bacteriologically clean slate" [11]. Accumulating evidence, however, has demonstrated that colonization of the fetus may begin much earlier than birth [14-16]. Using newer molecular techniques and high-throughput sequencing technology, an increasing number of groups have documented the presence of diverse bacterial communities in amniotic fluid, placental samples, and meconium $[3,13]$. Some have raised concerns that these newer techniques may be particularly prone to confounding issues secondary to contaminant DNA, especially given that few groups have demonstrated viable microorganisms in the fetal environment [13]. Though the question of whether true microbial colonization of infants begins before or after birth remains unclear, the large body of literature documenting differences in the microbiome of children born vaginally versus by CS points to the continued importance of mode of delivery in helping to shape the postnatal microbiome $[4,17-25]$. Though these differences have not been completely consistent in the literature, several important trends have emerged: (1) children born by CS (and elective CS in particular) exhibit a diminished overall diversity in their microbiome, (2) their microbiome appears to contain fewer of the bacterial species believed to be health inducing, and (3) there is a trend towards an increased prevalence of potentially pathogenic bacteria in their intestinal microbiome.

"Microbial richness" estimates the number of different bacterial taxa or species present and "microbial diversity" evaluates both the number of species and the evenness of their distribution in a sample [26]. The literature on the relationship between a cesarean mode of delivery and the infant microbiome has provided conflicting results on these measures. A few groups have found evidence of a persistent negative association between CS and infant microbial diversity and richness. For instance, Jakobsson et al. [20] performed bacterial gene pyrosequencing in 24 healthy term infants' stool samples and found that CS infants had a lower total microbial diversity compared to vaginally delivered (VD) infants, with differences persisting through the first 2 years of life. Similarly, Azad et al. [26] found that infants born by elective CS (i.e., CS before labor) had the lowest richness and diversity at 4 months of age. Sampling infants earlier (at 3 days of life), Biasucci et al. [18] also found increased inter- and intragroup bacterial taxonomy variations in VD infants compared to CS infants. Other groups have 
demonstrated similarly higher numbers of taxa in VD infants when looking at bacteria found in oral swab samples of infants [27, 28]. Notably, the recent report by Chu et al. [28], which documented a reduced oral cavity diversity in infants delivered by CS, found no differences in diversity when looking at the meconium microbial composition of infants delivered vaginally compared to those delivered by CS.

In contrast, some have noted findings in complete opposition to this notion that CS-delivered infants have less microbial diversity. For instance, Endesfelder et al. [17] reported a positive rather than negative association between the richness and bacterial abundance at the genus level and a history of being delivered by CS. Others have found that placental samples collected from CS births [23] or the meconium passed by CS infants in the first $48 \mathrm{~h}$ of life have a greater microbial diversity than samples collected from VD placentas and infants, respectively [29]. This increased heterogeneity in microbial samples from CS infants has been documented by some as being present even up to 1 year of age [19]. Finally, there are some groups which have reported mixed findings of a higher richness but less diversity in VD infants [4] or no diversity differences at all when comparing VD and CS-delivered infants [22, 30]. For instance, Azad et al. [26] found the lowest microbial diversity among electively CS infants but the highest microbial diversity at 4 months in infants delivered by emergency CS (i.e., CS after the onset of labor) - higher than even in the VD infants. Further work by this group has shown that structural differences that exist between VD infants and CS-delivered infants only persist through the first year of life for infants delivered by emergent CS [31].

There appears to be a much stronger consensus as to the differences that exist in the composition of the neonatal microbiome of CS versus VD infants than there is regarding purported differences in overall diversity or abundance. Many believe this to be due to the physical contact of VD infants with the birth canal, which is thought to be a major determinant of the microbial differences observed between CS and VD infants [14, 32, 33]. This theory is substantiated by reports that common vaginal microorganisms such as Lactobacillus, Prevotella, and Sneathia account for the majority of VD infants' bacterial communities [32]. In 2010, Dominguez-Bello et al. [34] published particularly convincing evidence of this hypothesis. They described the microbial communities of 10 mothers and their infants, 6 of whom were delivered by cesarean. Using samples taken from various body sites, they found that VD infants' microbial communities most resembled their own mother's vaginal microbiota, with a particular emphasis on Lactobacillus. In contrast, infants born via CS in their sample were colonized by bacteria that most resembled generic skin flora, not simply their own mother's specific skin bacterial community [34]. Others have also found that VD infants have more Lactobacillus specifically compared to infants delivered by CS $[4,23]$.

Bifidobacterium is another commonly isolated bacteria in fullterm, VD infants $[4,18]$ that has also been documented to be less abundant in infants delivered by CS [4, 18, 19, 21, 25, 35-39]. The magnitude of the difference in some cases is quite large, with some groups reporting the presence of Bifidobacterium in 56\% of their VD infants versus it being completely absent in their cohort of CS infants [18]. Others have commented on differences in abundance, with one group reporting that infants delivered vaginally had up to 1,300-fold higher levels of Bifidobacterium in their stool at 1 month of age [39]. In addition, some have found that infants born by CS did eventually become colonized with Bifidobacterium, but the colonization was delayed and counts remained one third to one half less than in VD infants [38]. Importantly, not all groups have found differences in Bifidobacterium communities. An analysis of 606 six-week old European infants from 5 countries found that mode of delivery had no effect on the relative proportions of Bifidobacterium in their infants [40]. That group found that Bifidobacterium and Bacteroides overall were most prevalent among all of their sampled infants but only Streptococcus and Coccidiodes species were different by mode of delivery and were most commonly found in CS-delivered infants [40].

Bacteroides, another common vaginal colonizer, may be another important organism that differentiates by mode of delivery. Many have found that infants born via CS have fewer Bacteroides than VD infants $[19,21,25,36,40,41]$, with one group reporting up to 100-fold lower median counts [21]. Others found delayed colonization [20] or no Bacteroides at all in their CS infants [23, 26]. These findings have even been discovered in preterm infants noted to be born with less amounts of Bacteroides at 29 weeks and who have slower rises in abundance when born via CS [42]. Differences in Bacteroides colonization may not, however, persist over time. Huurre et al. [39], for instance, found similar Bacteroides populations in their VD and CS infants at 1 month of age.

Compared to infants delivered vaginally, infants born via CS appear to be more commonly colonized by skin flora. For instance, Dominguez-Bello et al. [34] noted a predominance of Staphylococcus, Corynebacterium, and Proprionibacterium spp. in their CSdelivered infants. Similarly, a recent cohort of maternal-infant dyads sampled serially over the first 6 postnatal weeks found that, upon delivery, Propionibacterium and Streptococcus spp. were more common in CS infants, though notably that group found that microbial differences by mode of delivery were absent by 6 weeks [28]. Other groups have reported associations between CS birth and microbial colonization by potentially pathogenic species such as Klebsiella [35, 43], Haeomophilus [44], Clostridium [4, 5, 21, 25, 43, 44], Citrobacter [21], Escherichia coli [21], and Enterococcus, particularly after emergency CS [45]. Importantly, the microbial compositional differences attributable to CS may persist into adulthood, with one group finding higher levels of Haeomophilus and certain Clostridium genera in adults born by CS compared to adults born vaginally [44]. Again, however, these findings have not been consistent in the literature [46]. Recent studies noting inconsistencies within groups of CS-delivered infants have hypothesized that the occurrence of labor (i.e., the presence of contractions and/ or rupture of membranes) prior to the CS may be a stronger determinant of differential microbial colonization than simply a history of CS alone [28]. For instance, in one cohort of 81 maternal-infant dyads, neonates delivered via a CS that occurred before labor were primarily populated by microbiota found on maternal skin, whereas the taxa found on infants delivered via a CS after labor had occurred were more similar to the taxa of VD infants, i.e., communities which resembled maternal skin and vagina [28]. Thus, future studies may need to better delineate the circumstances under which CS occurred in order to more precisely define microbial differences by mode of delivery.

Pediatric Outcomes Linked to Cesarean-Associated Microbial Communities

Accumulating data suggests infants born via CS have physiologic and pathophysiologic differences at birth that are linked to adverse short-term and long-term health outcomes even after ac- 
counting for a potential increased risk of these outcomes due to maternal prepregnancy diagnoses $[6,47]$. In the immediate neonatal and infancy period, CS is most strongly associated with increased respiratory morbidity $[6,48,49]$, diminished initiation of breastfeeding $[6,50,51]$, relative hypothermia [47], and an increased risk of admission to an intensive care unit, particularly if conducted electively prior to 40 weeks $[51,52]$. When looking at childhood, adolescence, and even adulthood, individuals born by cesarean have been noted to have an increased risk of susceptibility to immune-related conditions, specifically asthma [6, 53-55], type I diabetes [56], allergic rhinitis [6], food allergies [6, 47], and celiac disease $[57,58]$. In addition, there are strong associations between CS birth and an altered body mass composition [8]. Individuals born via cesarean appear to have a higher propensity towards being overweight in childhood, adolescence, and even early adulthood, independently of the birth weight or known obesity risk factors $[7,59]$.

Some of these relationships appear to be mediated by the maternal history of atopy. For instance, the relationship between CS and food allergy appears to diminish if there is no maternal history of atopy [6]. Similarly, in one of the largest Brazilian cohort studies looking at CS and the risk of later obesity, adjusted models which took maternal prepregnancy weight into consideration found a substantially reduced risk, except for certain small subgroups of participants such as women in their early 20s [59]. However, for other outcomes, the relationship appears to withstand controlling for potential confounding by maternal prepregnancy diagnoses. For instance, Tollånes et al. [55] found that a maternal history of asthma did not change the increased risk of asthma seen among CS-delivered infants, and Cardwell et al. [56] documented a link between CS and type 1 diabetes after accounting for maternal diabetes. Given the relationship between birth by CS and these outcomes, the pressing question becomes one of pathophysiology. Increasing evidence suggests that the development of certain adverse health outcomes may be due at least in part to a neonatal microbial dysbiosis related to birth by CS. The evidence for this lies in the associations between the risk of certain disease processes and bacterial groups whose presence varies by mode of delivery. These associations are described below.

\section{Health Outcomes Associated with Bacterial Groups Less}

Common in CS-Delivered Infants

The bacteria found less commonly in infants born by CS are Lactobacillus, Bifidobacterium, Bacteroides, and Prevotella, which, as previously discussed, are common vaginal colonizers. Lactobacillus supplementation has been associated with a decreased risk of atopic conditions such as eczema and asthma [60], and functional studies have demonstrate that Lactobacillus may prevent asthma by reducing airway hyperresponsiveness and inflammatory cell invasion of lung tissue [61]. Lower abundances of Bifidobacterium have been linked to eczema [62], cirrhosis [63], and colorectal cancer [64]. During infancy, Bifidobacterium spp. are considered beneficial bacteria with reported protection against necrotizing enterocolitis in part by influencing gut barrier function [65]. Previous work has demonstrated that the protective impact of bifidobacterial species (e.g., Bifidobacterium bifidum and B. longum subsp. Infantis) during infancy is likely mediated by modification of the gut barrier function via utilization of human milk oligosaccharides [66]. The presence of Bifidobacterium in fecal samples in infancy has also been associated with a normal weight status by several groups $[67,68]$. The antiobesity effects of Bifidobacterium are supported by rodent models that demonstrated that administration of Bifidobacterium spp. to male Sprague-Dawley rats on a 5 -week high-fat diet resulted in reduced body fat and improved blood lipid levels [69]. Collectively, these data suggest that CS alters the infant microbiome and health outcomes, in part through specific microbe-host interactions that modify the infant lipid metabolism and inflammatory responses.

Importantly, not all associations with vaginally related microbiota are consistently positive. For instance, the presence of Prevotella has been negatively associated with both general inflammation [70] and type 1 diabetes among children [71]. However, pediatric obesity research studies have revealed that certain species of Prevotella may play a role in carbohydrate fermentation and the production of exogenous short-chain fatty acids)essential for obesity-associated microbiota [72-74]. In addition, the $\mathrm{H}_{2}$-producing Prevotella family has been found in the gastrointestinal tracts of obese subjects [75]. Thus, it is possible that different Prevotella spp. may play differential roles in the metabolism of their host; more literature is needed to tease out such differences. Similarly, despite the decreased risk of atopy reported with Lactobacillus colonization, the presence of some Lactobacillus species such as Lactobacillus reuteri has also been associated with obesity $[76,77]$. Bacteroides is a vaginal colonizer less frequently seen in CS-delivered infants that has been linked to worse, not better, outcomes. In a small case-control study of 32 children, children with type 1 diabetes displayed increased quantities of Bacteroides compared to healthy children [71]. In addition, just as for L. reuteri, colonization with higher levels of Bacteroides has been linked to obesity among children and adults [78-80].

Thus, it appears that some vaginal colonizers may have beneficial effects on human metabolic and inflammatory pathways while others may contribute to a worsened metabolism. The health-mediating role of certain microbes, therefore, appears to have more to do with the specific characteristics of each species than with the fact that they are vaginal colonizers.

\section{Health Outcomes Associated with Bacterial Groups Seen}

More Frequently after CS

The bacterial groups that appear to be more frequently found in the microbiome of CS-delivered infants and that have the most literature linking them to later childhood health outcomes are Staphylococcus and Clostridium. Colonization with increased amounts of Staphylococcus in the gut of children has been associated in some studies with a later development of atopic dermatitis [81-83]. However, other research has shown no association between Staphylococcus and other atopic conditions such as asthma [84]. Clostridium spp. have also been linked in the literature with atopic conditions, specifically atopic dermatitis and asthma. In a prospective cohort of 2,733 children, fecal colonization with Clostridium difficile at 1 month of age was associated with a greater than 2-fold risk of asthma and eczema throughout the first 6-7 years of life [5]. However, stratified analyses revealed that this increased risk was limited to children of parents who were atopic themselves [5].

\section{Other Maternal Factors Mitigating the Development of the} Neonatal Microbiome

It is clear from the above literature that mode of delivery does not fully explain either the construction of the neonatal microbi- 
ome or the relationship between early microbial colonization and later health outcomes. However, there is mounting evidence that other maternal factors such as antibiotic use, stress, diet, and breastfeeding also help to shape the neonatal microbiome and likely mediate the effect of mode of delivery on the infant microbial colonization patterns. For instance, high cumulative maternal stress has been linked to a decrease in the relative abundance of Lactobacillus and Bifidobacterium in infants and a higher abundance of potentially pathogenic flora such as Escherichia, Serratia, and Enterobacter [85]. In addition, Mandal et al. [86] noted an association between a higher maternal intake of saturated/monounsatured fat and fat-soluble vitamins and the presence of proinflammatory organisms such as Proteobacteria, Firmicutes, and Bacteroidetes in offspring. Chu et al. [87] described the same association between a high maternal fat intake and a relative abundance of Enterococcus (of the Firmicutes phylum) as well as a depletion of Bacteroides spp. during pregnancy and at 6 weeks of age, particularly in infants delivered via CS. Breastfeeding has also been seen to affect both the diversity and the abundance of microbiota in infants, with some recent data indicating that breastfed infants have less microbial diversity earlier and more diversity by 1 year of age [31].

The role of maternal antibiotics in the development of the infant microbiome and potential downstream effects on adverse pediatric health outcomes is one that merits particular attention [88]. "Intrapartum antibiotic prophylaxis" or IAP regimens are usually ordered for prophylaxis against vertically transmitted group B streptococcus infections in newborns or for operative skin prophylaxis prior to or during a CS. Extensive evidence has shown perioperative antibiotics to be highly effective in reducing maternal infectious complications after CS, with rates of endometritis and surgical site infections dropping by half after prophylactic intravenous perioperative antibiotics [89]. As a result, the American College of Obstetrics and Gynecologists (ACOG) recommends that all women undergoing CS receive broad-spectrum antibiotics $60 \mathrm{~min}$ prior to incision [90]. Although population studies have shown incomplete uptake of this recommendation, close to $60 \%$ of newborn born via CS are exposed to these broad-spectrum antibiotics [91]. When looking at all newborns irrespectively of mode of delivery, the proportion with antibiotic exposure is estimated to be about $40 \%$, which is still substantial [31].

Several studies have noted that antibiotic use during gestation is associated with a reduced bacterial diversity, and in particular with a lower abundance of Lactobacillus and Bifiobacterium in the offspring gut [92-97]. Others have noted an $84 \%$ increased risk of developing childhood obesity in children whose mothers received any kind of antibiotics prenatally [16]. A large cohort of Canadian infants concluded that all types of maternal antibiotics were associated with differences in the diversity of infants' postnatal microbial communities in both CS-delivered and VD infants [31]. IAP was also found to be associated with deficiencies in Bacteroides spp. and elevated levels of Firmicutes and Proteobacteria in infants up to a year of life. Interestingly, breastfeeding in this cohort appeared to rescue IAP-exposed infants in that they became less "deficient" in Bacteroides over time [31]. Most of these studies either looked at all antibiotic use or focused on the use of broad-spectrum medications such as those used for surgical prophylaxis. In one study that looked simply at narrow-coverage penicillin use for group B streptococcus prophylaxis, the only difference found was a reduction in Clostridium colonization among exposed infants

Cesarean Birth, the Microbiome, and

Pediatric Health and no differences in Bifidobacterium [93]. However, a more recent cohort study did conclude that even narrow-coverage penicillin use during vaginal deliveries was associated with a decreased abundance of Bifidobacterium and an increased abundance of Clostridium bacteria that persisted over the first 12 weeks of life [98].

This limited literature indicates that there are certain maternal factors that may independently help to determine the diversity, richness, and composition of the postnatal microbiome and some which need to be included at least as covariates when assessing the effect of mode of delivery on microbial colonization and downstream health outcomes. Some factors, like receipt of IAP, may worsen or at least help to explain the potential deleterious effect of cesarean delivery on an infant's microbiome, while others, like breastfeeding, may be able to mitigate the risk of microbial dysbiosis associated with birth by CS $[31,90]$. In addition, though there is evidence that receipt of any kind of antibiotic is associated with microbial changes in infants, there may be differences when comparing narrow- and broad-spectrum coverage. Given the unclear mechanisms through which such variables as pre-/perinatal antibiotic use, maternal stress, and maternal/infant diet alter the offspring microbiome and mediate the effect of CS on microbial development, further studies that take into account these overlapping relationships are merited.

\section{Conclusions}

CS is one of the most commonly performed procedures in the world and it is currently the most common operating room procedure in the USA [99]. The positive impact it has had on both maternal and neonatal morbidity and mortality is undeniable [41]. However, it is important for both obstetric and pediatric clinicians to be aware of the significant literature tying birth by CS to certain adverse short- and long-term health outcomes in infants and children. The epidemiologic differences in the microbial communities of infants delivered by CS compared to infants delivered vaginally may be mediating the differential risk CS-delivered children face with respect to disease processes related to autoimmunity and obesity. The majority of studies reviewed here highlight a decreased or delayed presence of common vaginal colonizers such as Bifidobacterium, Lactobacillus, Bacteroides, and Prevotella in infants delivered by CS and a concomitant increased prevalence of skin and gastrointestinal flora such as Staphylococcus, Enterococcus, and Clostridium. Furthermore, a growing number of cross-sectional and longitudinal observational studies suggest an association between microbes the abundance of which appear to be linked to CS and a variety of chronic conditions including obesity, metabolic disease, necrotizing enterocolitis, inflammatory bowel disease, liver disease, atopy, and asthma. Table 1 depicts a summary of these associations. 
Table 1. Summary of microbiota associated with cesarean delivery and related health outcomes

\begin{tabular}{|c|c|c|c|}
\hline $\begin{array}{l}\text { Observed association with } \\
\text { cesarean section }\end{array}$ & $\begin{array}{l}\text { Microbial group affected } \\
\text { (genus level) }\end{array}$ & $\begin{array}{l}\text { Specific disease/ } \\
\text { health condition }\end{array}$ & References \\
\hline \multirow[t]{3}{*}{$\begin{array}{l}\text { Decreased or delayed } \\
\text { colonization after cesarean } \\
\text { section }\end{array}$} & Bifidobacterium & $\begin{array}{l}\text { Necrotizing enterocolitis, } \\
\text { eczema, obesity, liver disease, } \\
\text { colorectal cancer }\end{array}$ & $\begin{array}{l}\text { Hong et al. [62], Chen et al. [63], } \\
\text { Lu and Ni [65], Kalliomaki et al. [67], } \\
\text { Luoto et al. [68], Tojo et al. [64] }\end{array}$ \\
\hline & Lactobacillus & Atopy, obesity & Million et al. [77] \\
\hline & Bacteroides & Obesity, type 1 diabetes & Murri et al. [71], Ignacio et al. [78] \\
\hline \multirow[t]{2}{*}{$\begin{array}{l}\text { Increased colonization after } \\
\text { cesarean section }\end{array}$} & Staphylococcus & Atopic dermatitis & $\begin{array}{l}\text { Bjorksten et al. [83], Kalliomake } \\
\text { et al. [67], Marrs et al. [82] }\end{array}$ \\
\hline & Clostridium & $\begin{array}{l}\text { Atopic disease including atopic } \\
\text { dermatitis and asthma }\end{array}$ & van Nimwegen et al. [5] \\
\hline
\end{tabular}

It is important to recognize that the microbiome may only be one of several potential etiologic pathways that explain the relationship between birth by CS and later adverse health outcomes. Studies have demonstrated that infants born via prelabor CS lack the gradual surge of stress hormones associated with the uterine contractions and fetal hypoxia normally experienced during vaginal delivery [54]. This altered stress response to birth may have maladaptive effects on the developing immune system directly through poor activation of the normal hormonal pathways or perhaps indirectly through stressrelated epigenetic changes leading to adverse gene methylation [54]. These nonmicrobial immunologic processes may help to explain the increased incidence of autoimmune-mediated adverse health outcomes in children born via CS; the microbiome is likely not the full story. This is especially true given that all of the studies reviewed here are epidemiological in nature and thus direct causation between microbial differences and adverse outcomes cannot be inferred. Whether microbial differences seen in CS versus VD infants are the cause or result of a particular health outcome that has been impacted by other variables cannot be determined from the studies we have reviewed. For example, it remains unclear whether the loss of anti-inflammatory bacteria, the gain of pathogenic bacteria, or both are to blame for the higher risk of the abnormal body mass composition leading to obesity seen in CS-delivered infants and children or whether CSdelivered obese children have altered microbial taxonomic signatures due to reasons wholly unrelated to mode of delivery. In cases where the former is true, a great deal of additional work is needed to better understand how certain characteristics of the human micro- biota result in a given disease. Additionally, it appears that microbial composition - not total abundances or diversity - may be key, especially given contradictory evidence regarding whether diversity is protective or deleterious. However, this must be confirmed. Rather than focusing on one specific taxonomic group, future investigative efforts would be well served by examining overall microbial diversity measures. Finally, future research should also seek to understand the ways in which other maternal prenatal factors such as antibiotic use, stress, or diet potentially mediate or alter the effect of birth by CS on the development of the neonatal microbial community.

Given the current literature, it may be possible that mode of delivery is simply a proxy or mediating covariate along the pathways leading to the establishment of the postnatal microbiome and not an independent determinant. Ultimately, what is clear is that mode of delivery plays an important role in the development of the postnatal microbiome but likely tells only part of the story. The search for a better understanding of the differential risk for and pathophysiology of common chronic childhood diseases and adverse adult health outcomes would be well served by more comprehensive investigations into all the pre- and perinatal factors that have the potential to contribute to the neonatal microbiome. This is particularly important given emerging strategies to inoculate CS-delivered infants with vaginal microbiota by exposing them to vaginal fluids immediately after birth [100]. Unintended consequences such as an increased risk of neonatal infection from such attempted microbial transfers or altered colonization may result from a lack of understanding of how prenatal exposures and mode of delivery 
interact to affect the risk of disease later on. Thus future investigations should aim to evaluate the way in which all such variables interact at the level of the individual maternal-infant dyad.

\section{Acknowledgement}

We thank Dr. David Allison for his guidance in developing and completing this project.

\section{Disclosure Statement}

The authors have no financial relationships relevant to this article to disclose.

\section{Funding Sources}

The work discussed in this article was supported by the Robin Hood Foundation.

\section{Author Contributions}

Drs. Montoya-Williams, Lemas, and Carson conceptualized and formulated this review, performed literature searches, reviewed and summarized the pertinent literature, drafted the initial paper, and approved the final paper as submitted. Drs. Spiryda and Neu provided intellectual expertise, critically reviewed and revised this paper, and approved the final paper as submitted. Mr. Patel and Ms. Carney organized and managed the data reported in this review, critically reviewed this paper, assisted with revisions, and approved the final paper as submitted.

\section{References}

1 Flint HJ, Scott KP, Louis P, Duncan SH: The role of the gut microbiota in nutrition and health. Nat Rev Gastroenterol Hepatol 2012; 9:577-589.

2 Prince AL, Antony KM, Ma J, Aagaard KM: The microbiome and development: a mother's perspective. Semin Reprod Med 2014;32: 14-22.

-3 Aagaard K, Ma J, Antony KM, Ganu R, Petrosino J, Versalovic J: The placenta harbors a unique microbiome. Sci Transl Med 2014;6: 237 ra65.

-4 Pandey PK, Verma P, Kumar H, Bavdekar A, Patole MS, Shouche YS: Comparative analysis of fecal microflora of healthy full-term Indian infants born with different methods of delivery (vaginal vs. cesarean): Acinetobacter sp. prevalence in vaginally born infants. J Biosci 2012;37:989-998

5 van Nimwegen FA, Penders J, Stobberingh EE, Postma DS, Koppelman GH, Kerkhof M, et al: Mode and place of delivery, gastrointestinal microbiota, and their influence on asthma and atopy. J Allergy Clin Immunol 2011; 128:948-955-3.

6 O'Shea TM, Klebanoff MA, Signore C: Delivery after previous cesarean: long-term outcomes in the child. Semin Perinatol 2010;34: 281-292.

-7 Goldani HS, Bettiol H, Barbieri M, Silva AM, Agranonik M, Morais MB, et al: Cesarean delivery is associated with an increased risk of obesity in adulthood in a Brazilian birth cohort study. Am J Clin Nutr 2011;93:13441347.

8 Li H, Zhou Y, Liu J: The impact of cesarean section on offspring overweight and obesity: a systematic review and meta-analysis. Int J Obes 2013;37:893-899.
9 Montoya-Williams D, Lemas DJ, Spiryda L, Patel K, Neu J, Carson TL: What are optimal cesarean section rates in the US and how do we get there? A review of evidence-based recommendations and interventions. J Womens Health (Larchmt) 2017;26:1285-1291.

10 Neu J, Rushing J: Cesarean versus vaginal delivery: long-term infant outcomes and the hygiene hypothesis. Clin Perinatol 2011;38:321331.

11 Bezirtzoglou E, Stavropoulou E: Immunology and probiotic impact of the newborn and young children intestinal microflora. Anaerobe 2011;17:369-374.

12 Fallani M, Amarri S, Uusijarvi A, Adam R, Khanna S, Aguilera M, et al: Determinants of the human infant intestinal microbiota after the introduction of first complementary foods in infant samples from five European centres. Microbiology 2011;157:1385-1392.

13 Perez-Muñoz ME, Arrieta M-C, Ramer-Tait AE, Walter J: A critical assessment of the "sterile womb" and "in utero colonization" hypotheses: implications for research on the pioneer infant microbiome. Microbiome 2017;5:48.

14 Prince AL, Antony KM, Ma J, Aagaard KM: The microbiome and development: a mother's perspective. Semin Reprod Med 2014;32: $14-22$.

15 Neu J, Rushing J: Cesarean versus vaginal delivery: long-term infant outcomes and the hygiene hypothesis. Clin Perinatol 2011;38:321331.

16 Mueller NT, Bakacs E, Combellick J, Grigoryan Z, Dominguez-Bello MG: The infant microbiome development: mom matters. Trends Mol Med 2015;21:109-117.

17 Endesfelder D, zu Castell W, Ardissone A, Davis-Richardson AG, Achenbach P, Hagen $\mathrm{M}$, et al: Compromised gut microbiota networks in children with anti-islet cell autoimmunity. Diabetes 2014;63:2006-2014.
18 Biasucci G, Rubini M, Riboni S, Morelli L, Bessi E, Retetangos C: Mode of delivery affects the bacterial community in the newborn gut. Early Hum Dev 2010;86:13-15.

19 Bäckhed F, Roswall J, Peng Y, Feng Q, Jia H, Kovatcheva-Datchary P, et al: Dynamics and stabilization of the human gut microbiome during the first year of life. Cell Host Microbe 2015;17:690-703.

-20 Jakobsson HE, Abrahamsson TR, Jenmalm MC, Harris K, Quince C, Jernberg C, et al: Decreased gut microbiota diversity, delayed Bacteroidetes colonisation and reduced Th1 responses in infants delivered by caesarean section. Gut 2014;63:559-566.

21 Penders J, Thijs C, Vink C, Stelma FF, Snijders B, Kummeling I, et al: Factors influencing the composition of the intestinal microbiota in early infancy. Pediatrics 2006;118: 511-521.

$22 \mathrm{Hu}$ J, Nomura Y, Bashir A, Fernandez-Hernandez H, Itzkowitz S, Pei Z, et al: Diversified microbiota of meconium is affected by maternal diabetes status. PLoS One 2013;8:e78257.

23 Doyle RM, Alber DG, Jones HE, Harris K, Fitzgerald F, Peebles D, et al: Term and preterm labour are associated with distinct microbial community structures in placental membranes which are independent of mode of delivery. Placenta 2014;35:1099-1101.

24 Collado MC, Cernada M, Baüerl C, Vento M, Pérez-Martínez G: Microbial ecology and host-microbiota interactions during early life stages. Gut Microbes 2012;3:352-365.

25 Hesla HM, Stenius F, Jäderlund L, Nelson R, Engstrand L, Alm J, et al: Impact of lifestyle on the gut microbiota of healthy infants and their mothers - the ALADDIN birth cohort. FEMS Microbiol Ecol 2014;90:791-801. 
26 Azad MB, Konya T, Maughan H, Guttman DS, Field CJ, Chari RS, et al: Gut microbiota of healthy Canadian infants: profiles by mode of delivery and infant diet at 4 months. Can Med Assoc J 2013;185:385-394.

-27 Lif Holgerson P, Harnevik L, Hernell O, Tanner ACR, Johansson I: Mode of birth delivery affects oral microbiota in infants. J Dent Res 2011;90:1183-1188.

28 Chu DM, Ma J, Prince AL, Antony KM, Seferovic MD, Aagaard KM: Maturation of the infant microbiome community structure and function across multiple body sites and in relation to mode of delivery. Nat Med 2017;23: 314-326.

29 Ardissone AN, de la Cruz DM, Davis-Richardson AG, Rechcigl KT, Li N, Drew JC, et al: Meconium microbiome analysis identifies bacteria correlated with premature birth PLoS One 2014;9:e90784.

-30 Liu D, Yu J, Li L, Ai Q, Feng J, Song C, et al: Bacterial community structure associated with elective cesarean section versus vaginal delivery in Chinese newborns. J Pediatr Gastroenterol Nutr 2015;60:240-246.

- 31 Azad M, Konya T, Persaud RR, Guttman DS, Chari R, Field C, et al: Impact of maternal intrapartum antibiotics, method of birth and breastfeeding on gut microbiota during the first year of life: a prospective cohort study. BJOG 2016;123:983-993.

-32 Dominguez-Bello MG, Costello EK, Contreras M, Magris M, Hidalgo G, Fierer N, et al: Delivery mode shapes the acquisition and structure of the initial microbiota across multiple body habitats in newborns. Proc Natl Acad Sci USA 2010;107:11971-11975.

33 Collado MC, Cernada M, Neu J, Pérez-Martínez G, Gormaz M, Vento M: Factors influencing gastrointestinal tract and microbiota immune interaction in preterm infants. Pediatr Res 2015;77:726-731.

- 34 Dominguez-Bello MG, Blaser MJ, Ley RE, Knight R: Development of the human gastrointestinal microbiota and insights from highthroughput sequencing. Gastroenterology 2011;140:1713-1719.

- 35 Dogra S, Sakwinska O, Soh S-E, Ngom-Bru C, Brück WM, Berger B, et al: Dynamics of infant gut microbiota are influenced by delivery mode and gestational duration and are associated with subsequent adiposity. MBio 2015;6: $1-9$.

- 36 Kabeerdoss J, Ferdous S, Balamurugan R, Mechenro J, Vidya R, Santhanam S, et al: Development of the gut microbiota in southern Indian infants from birth to 6 months: a molecular analysis. J Nutr Sci 2013;2:e18.

- 37 Sirilun S, Takahashi H, Boonyaritichaikij S, Chaiyasut C, Lertruangpanya P, Koga Y, et al: Impact of maternal bifidobacteria and the mode of delivery on Bifidobacterium microbiota in infants. Benef Microbes 2015;6:767774 .

-38 Makino H, Kushiro A, Ishikawa E, Kubota H, Gawad A, Sakai T, et al: Mother-to-infant transmission of intestinal bifidobacterial strains has an impact on the early development of vaginally delivered infant's microbiota. PLoS One 2013;8:e78331.

-39 Huurre A, Kalliomäki M, Rautava S, Rinne M, Salminen S, Isolauri E: Mode of delivery - effects on gut microbiota and humoral immunity. Neonatology 2008;93:236-240.

40 Fallani M, Young D, Scott J, Norin E, Amarri $\mathrm{S}$, Adam R, et al: Intestinal microbiota of 6-week-old infants across Europe: geographic influence beyond delivery mode, breast-feed ing, and antibiotics. J Pediatr Gastroenterol Nutr 2010;51:77-84.

41 Molina G, Weiser TG, Lipsitz SR, Esquivel MM, Uribe-Leitz T, Azad T, et al: Relationship between cesarean delivery rate and maternal and neonatal mortality. JAMA 2015; 314:2263-2270.

42 Gregory KE, LaPlante RD, Shan G, Kumar DV, Gregas M: Mode of birth influences preterm infant intestinal colonization with bacteroides over the early neonatal period. Adv Neonatal Care 2015;15:386-393.

43 Fouhy F, Ross RP, Fitzgerald GF, Stanton C, Cotter PD: Composition of the early intestinal microbiota: knowledge, knowledge gaps and the use of high-throughput sequencing to address these gaps. Gut Microbes 2012;3:203220.

44 Goedert JJ, Hua X, Yu G, Shi J: Diversity and composition of the adult fecal microbiome associated with history of cesarean birth or appendectomy: analysis of the American Gut Project. EBioMedicine 2014;1:167-172.

45 Nelun Barfod M, Magnusson K, Lexner MO, Blomqvist S, Dahlén G, Twetman S: Oral microflora in infants delivered vaginally and by caesarean section. Int J Paediatr Dent 2011; 21:401-406.

46 Gonzales-Marin C, Spratt DA, Millar MR, Simmonds M, Kempley ST, Allaker RP: Identification of bacteria and potential sources in neonates at risk of infection delivered by caesarean and vaginal birth. J Med Microbiol 2012;61:31-41.

47 Hyde MJ, Mostyn A, Modi N, Kemp PR: The health implications of birth by caesarean section. Biol Rev 2012;87:229-243.

48 Doan E, Gibbons K, Tudehope D: The timing of elective caesarean deliveries and early neonatal outcomes in singleton infants born 37-41 weeks' gestation. Aust NZ J Obstet Gynaecol 2014;54:340-347.

49 Natile M, Ventura ML, Colombo M, Bernasconi D, Locatelli A, Plevani C, et al: Shortterm respiratory outcomes in late preterm in fants. Ital J Pediatr 2014;40:52.

-50 Esteves TM, Daumas RP, Oliveira MI, Andrade CA, Leite IC: Factors associated to breastfeeding in the first hour of life: systematic review. Rev Saude Publica 2014;48:697708.

51 Tzur T, Weintraub AY, Sheiner E, Wiznitzer A, Mazor M, Holcberg G: Timing of elective repeat caesarean section: maternal and neonatal morbidity and mortality. J Matern Neonatal Med 2011;24:58-64.
52 Riskin A, Gonen R, Kugelman A, Maroun E, Ekhilevitch G: Does cesarean section before the scheduled date increase the risk of neonatal morbidity? Isr Med Assoc J 2014;16:559-563.

53 Magnus MC, Håberg SE, Stigum H, Nafstad P, London SJ, Vangen S, et al: Delivery by cesarean section and early childhood respiratory symptoms and disorders: the Norwegian Mother and Child Cohort Study. Am J Epidemiol 2011;174:1275-1285.

54 Cho CE, Norman M: Cesarean section and development of the immune system in the offspring. Am J Obstet Gynecol 2013;208:249254.

55 Tollånes MC, Moster D, Daltveit AK, Irgens LM: Cesarean section and risk of severe childhood asthma: a population-based cohort study. J Pediatr 2008;153:112-116.

-56 Cardwell CR, Stene LC, Joner G, Cinek O, Svensson J, Goldacre MJ, et al: Caesarean section is associated with an increased risk of childhood-onset type 1 diabetes mellitus: a meta-analysis of observational studies. Diabetologia 2008;51:726-735

57 Decker E, Engelmann G, Findeisen A, Gerner $\mathrm{P}$, Laass M, Ney D, et al: Cesarean delivery is associated with celiac disease but not inflammatory bowel disease in children. Pediatrics 2010;125:e1433-e1440.

58 Mårild K, Stephansson O, Montgomery S, Murray JA, Ludvigsson JF: Pregnancy outcome and risk of celiac disease in offspring: a nationwide case-control study. Gastroenterology 2012;142:39-45.e3.

59 Barros FC, Matijasevich A, Hallal PC, Horta BL, Barros AJ, Menezes AB, et al: Cesarean section and risk of obesity in childhood, adolescence, and early adulthood: evidence from 3 Brazilian birth cohorts. Am J Clin Nutr 2012;95:465-470.

60 Kuitunen M, Kukkonen K, Juntunen-Backman K, Korpela R, Poussa T, Tuure T, et al: Probiotics prevent IgE-associated allergy until age 5 years in cesarean-delivered children but not in the total cohort. J Allergy Clin Immunol 2009;123:335-341.

61 Yu J, Jang S-O, Kim B-J, Song Y-H, Kwon J-W, Kang M-J, et al: The effects of Lactobacillus rhamnosus on the prevention of asthma in a murine model. Allergy Asthma Immunol Res 2010;2:199-205.

62 Hong P-Y, Lee BW, Aw M, Shek LPC, Yap $\mathrm{GC}$, Chua KY, et al: Comparative analysis of fecal microbiota in infants with and without eczema. PLoS One 2010;5:e9964.

63 Chen Y, Yang F, Lu H, Wang B, Chen Y, Lei $\mathrm{D}$, et al: Characterization of fecal microbial communities in patients with liver cirrhosis. Hepatology 2011;54:562-572.

64 Tojo R, Suarez A, Clemente MG, de los ReyesGavilan CG, Margolles A, Gueimonde M, et al: Intestinal microbiota in health and disease: role of bifidobacteria in gut homeostasis. World J Gastroenterol 2014;20:15163-15176.

65 Lu C-Y, Ni Y-H: Gut microbiota and the development of pediatric diseases. J Gastroenterol 2015;50:720-726. 
-66 Sela DA, Chapman J, Adeuya A, Kim JH, Chen F, Whitehead TR, et al: The genome sequence of Bifidobacterium longum subsp. infantis reveals adaptations for milk utilization within the infant microbiome. Proc Natl Acad Sci USA 2008; 105:18964-18969.

67 Kalliomaki M, Collado MC, Salminen S, Isolauri E: Early differences in fecal microbiota composition in children may predict overweight. Am J Clin Nutr 2008;87:534-538.

68 Luoto R, Kalliomäki M, Laitinen K, Delzenne NM, Cani PD, Salminen S, et al: Initial dietary and microbiological environments deviate in normal-weight compared to overweight children at 10 years of age. J Pediatr Gastroenterol Nutr 2011;52:90-95.

-69 An HM, Park SY, Lee DK, Kim JR, Cha MK, Lee SW, et al: Antiobesity and lipid-lowering effects of Bifidobacterium spp. in high fat dietinduced obese rats. Lipids Health Dis 2011;10: 116.

-70 Sher JU, Sczesnak A, Longman RS, Segata N, Ubeda C, Rostron T, et al: Expansion of intestinal Prevotella copri correlates with enhanced susceptibility to arthritis. Elife 2013;2:e01202.

-71 Murri M, Leiva I, Gomez-Zumaquero JM, Tinahones FJ, Cardona F, Soriguer F, et al: Gut microbiota in children with type 1 diabetes differs from that in health children: a casecontrol study. BMC Med 2013;11:46.

-72 Michail S, Lin M, Frey MR, Fanter R, Paliy O, Hilbush B, et al: Altered gut microbial energy and metabolism in children with non-alcoholic fatty liver disease. FEMS Microbiol Ecol 2015;91:1-9.

-73 Salminen S, Bouley C, Boutron-Ruault MC, Cummings JH, Franck A, Gibson GR, et al: Functional food science and gastrointestinal physiology and function. Br J Nutr 1998;80 (suppl 1):S147-S171.

-74 Pouteau E, Nguyen P, Ballèvre O, Krempf M: Production rates and metabolism of shortchain fatty acids in the colon and whole body using stable isotopes. Proc Nutr Soc 2003;62: 87-93.

-75 Zhang H, DiBaise JK, Zuccolo A, Kudrna D, Braidotti M, Yu Y, et al: Human gut microbiota in obesity and after gastric bypass. Proc Natl Acad Sci USA 2009;106:2365-2370.

76 Bervoets L, Van Hoorenbeeck K, Kortleven I, Van Noten C, Hens N, Vael C, et al: Differences in gut microbiota composition between obese and lean children: a cross-sectional study. Gut Pathog 2013;5:10.

-77 Million M, Maraninchi M, Henry M, Armougom F, Richet H, Carrieri P, et al: Obesityassociated gut microbiota is enriched in Lactobacillus reuteri and depleted in Bifidobacterium animalis and Methanobrevibacter smithii. Int J Obes (Lond) 2012;36:817-825.
Ignacio A, Fernandes MR, Rodrigues VA, Groppo FC, Cardos AL, Avila-Campo MJ, et al: Correlation between body mass index and faecal microbiota from children. Clin Microbiol Infect 2016;22:258.

79 Schwiertz A, Taras D, Schäfer K, Beijer S, Bos $\mathrm{N}$, Donus C, et al: Microbiota and SCFA in lean and overweight healthy subjects. Obesity (Silver Spring) 2010;18:190-195.

80 Abdallah IN, Ragab SH, Abd Elbaky A, Shoeib ARS, Alhosary Y, Fekry D: Frequency of Firmicutes and Bacteroidetes in gut microbiota in obese and normal weight Egyptian children and adults. Arch Med Sci 2011;7:501-507.

81 Kalliomäki M, Kirjavinen P, Eerola E, Kero P, Salminen S, Isolauri E: Distinct patterns of neonatal gut microflora in infants in whom atopy was and was not developing. Am J Clin Nutr 2001;107:129-134.

82 Marrs T, Bruce KD, Logan K, Rivett DW, Perkin MR, Lack G, et al: Is there an association between microbial exposure and food allergy? A systematic review. Pediatr Allergy Immunol 2013;24:311-320.e8.

83 Bjorksten B, Sepp E, Julge K, Voor T, Mikelsaar M: Allergy development and the intestinal microflora during the first year of life. J Allergy Clin Immunol 2001;108:516-520.

84 Keski-Nisula L, Katila M-L, Remes S, Heinonen S, Pekkanen J: Intrauterine bacterial growth at birth and risk of asthma and allergic sensitization among offspring at the age of 15-17 years. J Allergy Clin Immunol 2009; 123:1305-1311.

85 Zijlmans MAC, Korpela K, Riksen-Walraven JM, de Vos WM, de Weerth C: Maternal prenatal stress is associated with the infant intestinal microbiota. Psychoneuroendocrinology 2015;53:233-245.

86 Mandal S, Godfrey KM, McDonald D, Treuren WV, Bjørnholt JV, Midtvedt T, et al: Fat and vitamin intakes during pregnancy have stronger relations with a pro-inflammatory maternal microbiota than does carbohydrate intake. Microbiome 2016;4:55.

87 Chu DM, Antony KM, Ma J, Prince AL, Showalter L, Moller M, et al: The early infant gut microbiome varies in association with a maternal high-fat diet. Genome Med 2016;8:77.

88 Lemas DJ, Yee S, Cacho N, Miller D, Cardel M, Gurka M, et al: Exploring the contribution of maternal antibiotics and breastfeeding to development of the infant microbiome and pediatric obesity. Semin Fetal Neonatal Med 2016;21:406-409.

89 Weinstein RA, Boyer KM: Antibiotic prophylaxis for cesarean delivery - when broader is better. N Engl J Med 2016;375:1284-1286.

90 American College of Obstetricians and Gynecologists: ACOG Practice Bulletin No. 120: use of prophylactic antibiotics in labor and delivery. Obstet Gynecol 2011;117:14721483 .
-91 Brubaker SG, Friedman AM, Cleary KL, Prendergast E, D'Alton ME, Ananth CV, et al: Patterns of use and predictors of receipt of antibiotics in women undergoing cesarean delivery. Obstet Gynecol 2014;124:338344.

92 Mshvildadze M, Neu J, Shuster J, Theriaque D, Li N, Mai V: Intestinal microbial ecology in premature infants assessed with nonculture-based techniques. J Pediatr 2010; 156:20-25.

93 Jauréguy F, Carton M, Panel P, Foucaud P, Butel M-J, Doucet-Populaire F: Effects of intrapartum penicillin prophylaxis on intestinal bacterial colonization in infants. J Clin Microbiol 2004;42:5184-5188.

94 Keski-Nisula L, Kyynäräinen H-R, Kärkkäinen U, Karhukorpi J, Heinonen S, Pekkanen J: Maternal intrapartum antibiotics and decreased vertical transmission of Lactobacillus to neonates during birth. Acta Paediatr 2013;102:480-485.

-95 Aloisio I, Mazzola G, Corvaglia LT, Tonti G, Faldella G, Biavati B, et al: Influence of intrapartum antibiotic prophylaxis against group B Streptococcus on the early newborn gut composition and evaluation of the antiStreptococcus activity of Bifidobacterium strains. Appl Microbiol Biotechnol 2014;98: 6051-6060

-96 Fouhy F, Guinane CM, Hussey S, Wall R, Ryan CA, Dempsey EM, et al: High-throughput sequencing reveals the incomplete, short-term recovery of infant gut microbiota following parenteral antibiotic treatment with ampicillin and gentamicin. Antimicrob Agents Chemother 2012;56:5811-5820.

97 Tanaka S, Kobayashi T, Songjinda P, Tateyama A, Tsubouchi M, Kiyohara C, et al: Influence of antibiotic exposure in the early postnatal period on the development of intestinal microbiota. FEMS Immunol Med Microbiol 2009;56:80-87.

-98 Stearns JC, Simioni J, Gunn E, McDonald H, Holloway AC, Thabane L, et al: Intrapartum antibiotics for GBS prophylaxis alter colonization patterns in the early infant gut microbiome of low risk infants. Sci Rep 2017;7: 16527.

99 Pfuntner A, Wier LM, Stocks C: Most Frequent Procedures Performed in US Hospitals, 2010: Statistical Brief No 149. Rockville, Agency for Healthcare Research and Quality, 2006.

100 Dominguez-Bello MG, De Jesus-Laboy KM, Shen N, Cox LM, Amir A, Gonzalez A, et al: Partial restoration of the microbiota of cesarean-born infants via vaginal microbial transfer. Nat Med 2016;22:250-253.
Cesarean Birth, the Microbiome, and Pediatric Health
Neonatology 2018;114:103-111 DOI: $10.1159 / 000487102$ 